\title{
ANALISIS BENTUK MIKROPLASTIK PADA KERANG HIJAU (Perna viridis) DI ALUE NAGA KECAMATAN SYIAH KUALA KOTA BANDA ACEH
}

\author{
Fitria Wulan Sari ${ }^{1}$, Mimie Saputri ${ }^{2}$, Devi Syafrianti ${ }^{3}$, Dewi Andayani ${ }^{4}$, M. Ali Sarong ${ }^{5}$ \\ Program Studi Pendidikan Biologi FKIP Unsyiah \\ Email: fitriawulansari.bio17@fkip.unsyiah.ac.id
}

\begin{abstract}
ABSTRAK
Kerang hijau (Perna viridis) merupakan salah hewan dari kelas bivalvia yang berhabitat di kawasan perairan estuari, teluk dan daerah mangrove. Kerang hijau termasuk kedalam kelompok suspension feeder yaitu memakan apa saja yang ada disekitarnya sehingga kerang hijau dapat mengakumulasi mikroplastik. Penelitian ini bertujuan untuk menganalisis bentuk mikroplastik yang ditemukan pada sampel kerang hijau (Perna viridis) di Alue Naga, Kecamatan Syiah Kuala, Kota Banda Aceh.Penelitian ini dilakukan pada bulan Mei-Juni 2021. Pengambilan data dengan menggunakan metode survei yang menggunakan teknik random sampling. Objek penelitian ini yaitu berupa kerang hijau (Perna viridis) yang diperoleh dari kawasan Alue Naga, Kecamatan Syiah Kuala, Kota Banda Aceh. Parameter yang diamati pada penelitian ini adalah bentuk mikroplastik yang terdapat pada kerang hijau (Perna viridis). Data dianalisis secara deskriptif yang ditampilkan dalam bentuk gambar dan tabel berdasarkan bentuk mikroplastiknya. Hasil penelitian diperoleh bahwa mikroplastik di kawasan Alue Naga ditemukan dalam 4 bentuk mikroplastik yaitu, bentuk fiber, fragmen, film, dan pelet.
\end{abstract}

Kata kunci: Bentuk, Mikroplastik, Kerang Hijau, Alue Naga

\begin{abstract}
Green mussel (Perna viridis) is an animal from the bivalves class that lives in estuarine waters, bays and mangrove areas. Green mussels are included in the suspension feeder group, which means they eat whatever is around them so that green mussels can accumulate microplastics. This study aims to analyze the form of microplastics found in green samples (Perna viridis) in Alue Naga, Syiah Kuala District, Banda Aceh City. The object of this research is in the form of green mussels (Perna viridis) obtained from the Alue Naga area, Syiah Kuala District, Banda Aceh City. The parameter observed in this study was the form of microplastics found in green mussels (Perna viridis). The data were analyzed descriptively which were displayed in the form of pictures and tables based on the shape of the microplastic. The results showed that microplastics in the Alue Naga area were found in 4 forms of microplastics, namely, the form of fiber, fragments, films, and pellets.
\end{abstract}

Keywords: Shape, Microplastic, Green Mussels, Alue Naga

\section{PENDAHULUAN}

Salah satu ancaman serius bagi Sampah plastik memberikan dampak ekosistem laut adalah sampah plastik. terhadap 690 spesies laut. Mikroplastik 
banyak ditemui pada daerah laut yang dekat dengan aktivitas manusia. Ukuran mikroplastik yang kecil cenderung mudah masuk dan terakumulasi pada organisme laut (Mardiyana dan Kristiningsih, 2020).

Mikroplastik memiliki ukuran 0,3 $\mathrm{mm}-5 \mathrm{~mm}$ dan biasanya memiliki bentuk seperti fragmen, film, dan fiber (Nor dan Obbard, 2014). Mikroplastik jenis fiber berbentuk seperti jaring nelayan dan akan berwarna biru ketika terkena lampu ultraviolet, jenis film memiliki bentuk seperti lembaran, sedangkan jenis fragmen berbentuk seperti pecahan plastik (Septian, 2014).

Mikroplastik bisa menimbulkan ancaman serius untuk spesies laut termasuk spesies yang menduduki tingkat trofik lebih rendah, contohnya adalah plankton, yang memiliki sifat filter feeder dan mengkonsumsi mikroplastik, serta memiliki dampak terhadap spesies yang menduduki tingkatan trofik yang lebih tinggi melalui proses bioakumulasi (Joesidawati, 2018) hingga mikroplastik juga bisa membahayakan manusia yang mengkonsumsi spesies laut yang sudah tercemar (Mulu dkk., 2020).

Salah satu biota perairan yang mampu mengakumulasi mikroplastik salah satunya adalah kerang hijau. Kerang hijau (Perna viridis) ini dianggap sebagai bioindikator yang baik dalam merespon perubahan pada lingkungan. Spesies kerang yang hidup di lingkungan estuari harus memiliki kemampuan untuk mentoleransi kondisi perairan yang ekstrim. Kerang termasuk hasil perairan yang dibutuhkan oleh tubuh manusia dan memiliki nilai gizi yang tinggi (Temmy dan Widyorini, 2017).

Berdasarkan penelitian dari Wahdani., dkk (2020) di perairan Maccini Baji, Kecamatan Labakkang, Kabupaten Pangkajen Kepulauan, Sulawesi Selatan menunjukkan bahwa di dalam tubuh kerang terdapat partikel mikroplastik. Kerang hijau juga termasuk organisme filter feeder yaitu hewan yang memakan apa saja yang ada di sekelilingnya, termasuk partikel dan materi organik. Dengan demikian mikroplastik bisa masuk ke dalam tubuh kerang (Widianarko dan Hantoro, 2018).

Salah satu produk perikanan dari perairan Alue Naga yang banyak di konsumsi oleh masyarakat adalah kerang hijau. Alue Naga termasuk salah satu gampong yang berada di Kecamatan Syiah Kuala Kota Banda Aceh yang berbatasan langsung dengan Selat Malaka dan berada di wilayah pesisir (Zalmita dkk., 2020). Aktivitas masyarakat yang menghasilkan degradasi sampah plastik dan aktivitas para nelayan yang menggunakan tali yang terbuat dari bahan plastik dikawasan habitat 
kerang hijau di Alue Naga diperkirakan mengandung mikroplastik.

Penelitian ini dilakukan untuk menganalisis bentuk mikroplastik yang teridentifikasi pada sampel kerang hijau (Perna viridis) di Alue Naga, Kecamatan Syiah Kuala, Kota Banda Aceh.

\section{METODE PENELITIAN}

\section{a. Waktu dan Tempat Penelitian}

Penelitian dilakukan di Gampong Alue Naga, Kecamatan Syiah Kuala, Kota Banda Aceh dan di Laboratorium Pendidikan Biologi Fakultas Keguruan dan Ilmu Pendidikan USK. Pelaksanaan penelitian dilakukan pada bulan Mei-Juni 2021.

\section{b. Pendekatan dan Jenis Penelitian}

Pendekatan yang digunakan berupa pendekatan kuantitatif dengan jenis penelitian secara deskriptif.

\section{c. Metode Penelitian}

Metode yang digunakan dalam penelitian ini adalah metode survei dengan menetapkan lokasi pengambilan sampel secara random sampling. Objek yang diteliti adalah spesies kerang hijau (Perna viridis) yang diperoleh dari gampong Alue Naga, Kecamatan Syiah Kuala, Kota Banda Aceh. Parameter yang diamati berupa bentuk mikroplastik pada sampel kerang hijau.

\section{d. Pengumpulan Data}

Pengumpulan data diawali dengan pengambilan spesies kerang hijau di perairan Gampong Alue Naga. Spesies kerang hijau dikelompokkan berdasarkan ukuran panjang cangkangnya, selanjutnya kerang hijau tersebut diidentifikasi mikroplastik yang ditemukan dengan menggunakan mikroskop stereo dengan pembesaran 40x dan kemudian diidentifikasi berdasarkan bentuk mikroplastik yang ditemukan dan kemudian dicatat pada tabel pengamatan.

\section{e. Analisis Data}

1. Sampel yang Dibutuhkan

Jumlah sampel yang dibutuhkan dihitung dengan formulasi rumus:

$$
\mathrm{n}=\frac{\mathrm{N}}{1+\mathrm{N}\left(\mathrm{d}^{2}\right)}
$$

(Yamane, 1967).

Dimana:

$\mathrm{n}=$ jumlah sampel yang dibutuhkan

$\mathrm{N}=$ populasi seluruhnya (jumlah seluruh kerang dalam 3 kelas) $\mathrm{d}=$ tingkat kepercayaan $5 \%$

\section{Sampel Setiap Kelas}

Untuk menentukan jumlah sampel setiap kelas ukuran kerang hijau dihitung dengan menggunakan rumus alokasi proporsional menurut (Sugiyono, 2007).

$$
\mathrm{ni}=\frac{\mathrm{Ni}}{\mathrm{N}} \times \mathrm{n}
$$


Dimana:

ni=jumlah sampel yang dibutuhkan pada kelas i

$\mathrm{n}=$ jumlah sampel yang dibutuhkan

$\mathrm{N}=$ populasi seluruhnya (jumlah seluruh

kerang dalam 3 kelas)

$\mathrm{Ni}=$ populasi pada kelas $\mathrm{i}$

Data yang telah diidentifikasi dari penelitian ini selanjutnya dianalisis secara deskriptif, dan disajikan dalam tabel dan gambar berdasarkan bentuk mikroplastiknya.

\section{HASIL PENELITIAN}

Hasil identifikasi mikroplastik dengan menggunakan mikroskop stereo pada pembesaran $40 \mathrm{x}$ diperoleh total keseluruhan mikroplastik berjumlah 70 item, yang terdapat di dalam 60 sampel kerang hijau. Jumlah sampel kerang hijau yang mengandung mikroplastik di kawasan Alue Naga, Kecamatan Syiah Kuala, Kota Banda Aceh disajikan dibawah ini.

\begin{tabular}{|c|c|c|c|c|c|c|}
\hline \multirow{2}{*}{$\begin{array}{l}\text { Kelas Ukuran } \\
\text { Panjang } \\
\text { Cangkang }\end{array}$} & \multirow{2}{*}{$\begin{array}{c}\text { Keseluruha } \\
\text { nSampel } \\
\text { Kerang } \\
\text { Hijau } \\
\text { (Individu) }\end{array}$} & \multirow{2}{*}{$\begin{array}{c}\text { Jumlah } \\
\text { Mikroplastik } \\
\text { pada Spesies } \\
\text { Kerang Hijau } \\
\quad \text { (Item) }\end{array}$} & \multicolumn{4}{|c|}{$\begin{array}{l}\text { Kerang Hijau yang Memiliki } \\
\text { Mikroplastik Bentuk Fiber, } \\
\text { Fragmen, Film, dan Pelet (Item) }\end{array}$} \\
\hline & & & Fiber & Fragmen & $\begin{array}{c}\text { Fil } \\
\mathrm{m}\end{array}$ & Pelet \\
\hline $\mathrm{A}(4-5,9 \mathrm{~cm})$ & 20 & 21 & 14 & 3 & 2 & 2 \\
\hline $\mathrm{B}(6-7,9 \mathrm{~cm})$ & 20 & 24 & 14 & 5 & 2 & 3 \\
\hline $\mathrm{C}(8-10 \mathrm{~cm})$ & 20 & 25 & 17 & 3 & 1 & 4 \\
\hline Total & 60 & 70 & 45 & 11 & 5 & 9 \\
\hline
\end{tabular}

Tabel 1.Jumlah Sampel Kerang Hijau yang Mengandung Mikroplastik di Alue Naga, Kecamatan Syiah Kuala, Kota Banda Aceh

Sampel kerang hijau teridentifikasi terdapat dalam 4 bentuk mikroplastik yaitu bentuk fiber, film, pelet, dan fragmen. Gambar bentuk miroplastik yang pada sampel kerang hijau dikawasan Alue Naga, Kecamatan Syiah Kuala, Kota Banda Aceh disajikan pada gambar berikut ini. 


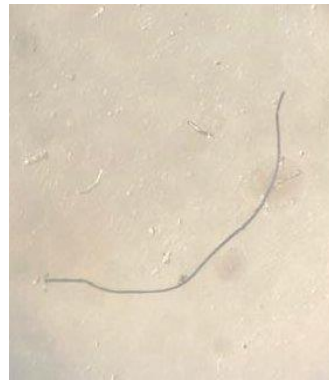

a

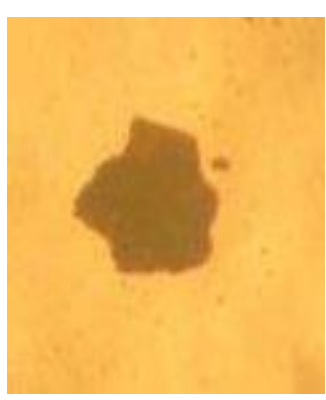

b

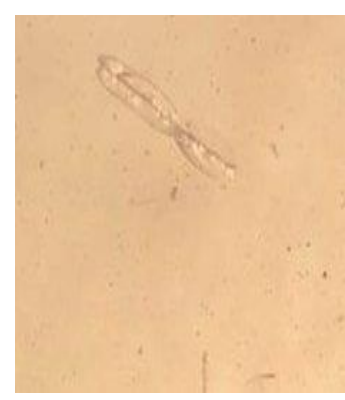

c

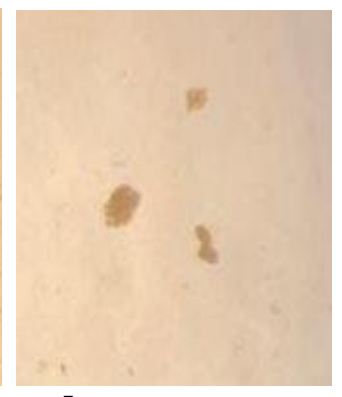

d

Gambar 1. Bentuk Mikroplastik yang Terdapat di Sampel Kerang Hijau

a (Fiber), b (Fragmen), c (Film), d (Pelet)

Jenis mikroplastik di kawasan Alue Naga yang paling dominan ditemukan berupa bentuk fiber yaitu sebanyak 45 item atau sebanyak $64 \%$, bentuk fragmen adalah bentuk kedua terbanyak yaitu sebanyak 11 item atau sebanyak $16 \%$, kemudian yang ketiga adalah bentuk pelet yaitu sebanyak 9 item atau sebanyak $13 \%$, dan jenis mikroplastik yang paling sedikit ditemukan yaitu bentuk film sebanyak 5 item atau sebanyak $7 \%$.

Mikroplastik yang paling banyak ditemukan adalah bentuk fiber. Woods (2018) menambahkan bahwa 90\% yang tersebar di perairan adalah bentuk fiber.
Pernyataan tersebut berikatan dengan aktivitas masyarakat dan aktivitas para nelayan yang menggunakan tali berbahan plastik. Mikroplastik paling sedikit terdapat pada bentuk film, hal ini menunjukkan bahwa masyarakat dikawasan Alue Naga tidak terlalu sering menggunakan kantong plastik.

Jumlah mikroplastik fiber, fragmen, film, dan pelet yang ditemukan pada sampel kerang hijau di kawasan Alue Naga, Kecamatan Syiah Kuala, Kota Banda Aceh disajikan pada gambar berikut.

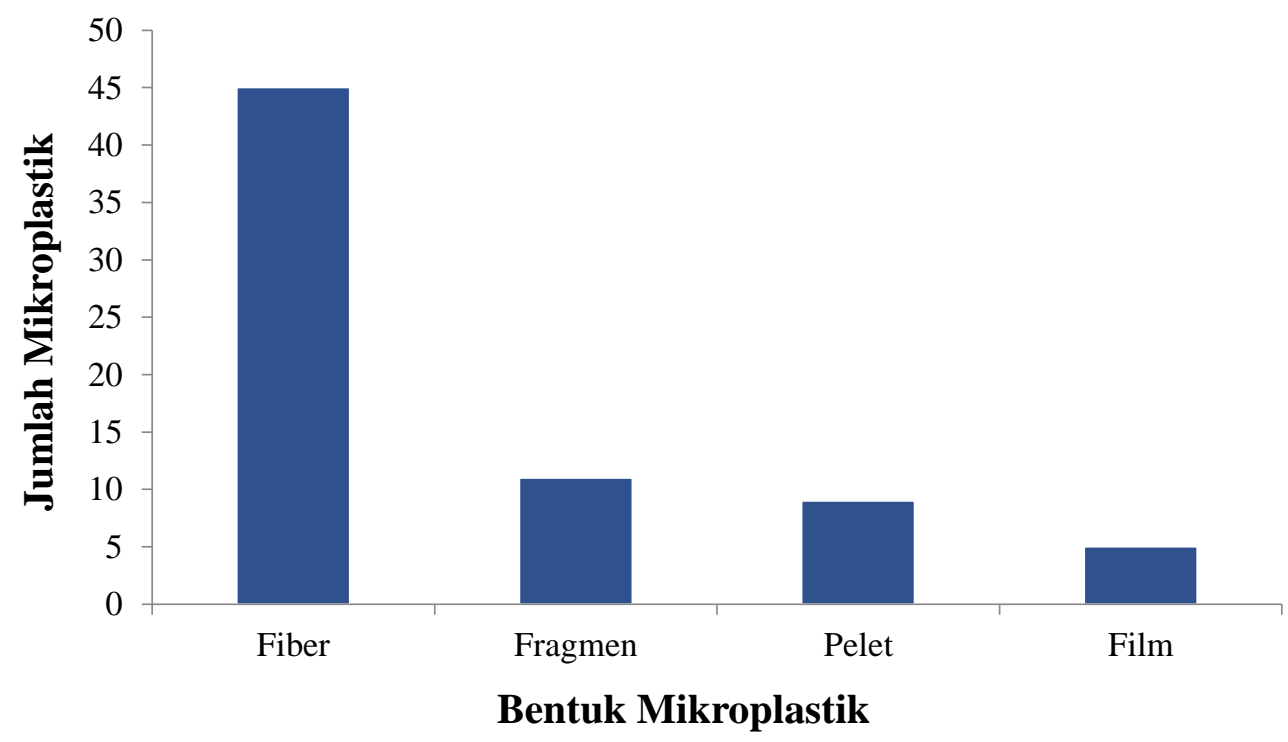

Gambar 2. Jumlah Bentuk Mikroplastik di Kawasan Alue Naga 
Berdasarkan penelitian yang telah dilakukan menunjukkan bahwa spesies kerang hijau dari Gampong Alue Naga, Kecamatan Syiah Kuala, Kota Banda Aceh mengandung mikroplastik serta menunjukkan bahwa perairan di kawasan Alue Naga, Kecamatan Syiah Kuala, Kota Banda Aceh telah tercemar mikroplastik yang berasal dari kegiatan perikanan oleh para nelayan dan plastik yang terdegradasi ketika digunakan oleh warga sekitar dalam kesehariannya. Diharapkan kesadaran masyarakat untuk mengurangi penggunaan sampah plastik agar sampah plastik di perairan bisa berkurang.

\section{KESIMPULAN}

Kesimpulan dari penelitian ini adalah mikroplastik yang ditemukan di kawasan Alue Naga ditemukan dalam 4 bentuk mikroplastik yaitu, fiber, fragmen, film, dan pelet.

\section{DAFTAR PUSTAKA}

Joesidawati, M. I. 2018. Pencemaran Mikroplastik di Sepanjang Pantai Kabupaten Tuban. Prosiding Seminar Nasional Hasil Penenlitian dan Pengabdian Kepada Masyarakat. 3(1): 8-15.

Mardiyana., A, Kristiningsih. 2020. Dampak Pencemaran Mikroplastik di Ekosistem Laut Terhadap Zooplankton: Review. Jurnal Pengendalian Pencemaran Lingkungan (JPPL). 2(1): 29-36.
Mulu, M., R, Hudin., Y, W. Dasor., V, Tarsan. 2020. Marine Debris dan Mikroplastik: Upaya Mencegah Bahaya dan Dampaknya di Tampode, Desa Salama, Kabupaten Manggarai, NTT. Jurnal Pengabdian Kepada Masyarakat. 3(2): 79-84.

Nor, M. N. H., J, P. Obbard. 2014. Microplastics in Singapore's Coastal Ecosystems. Marine Pollution Bulltein. 79(1-2): 278-283.

Septian. 2014. Sebaran Spasial Mikroplastik di Sedimen pada Pantai Pangandaran Jawa Barat. Jurnal Geomaritim Indonesia. 1(1): 1-8.

Sugiyono. 2007. Statistik Untuk Penelitian. Bandung: Penerbit Alfabeta.

Temmy, S. A., N, Widyorini. 2017. Tingkat Kerja Osmotik dan Pertumbuhan Kerang Hijau Perna viridis yang Dikultivasi di Perairan Tambak Lorok Semarang. Journal of Maquares. 6(2): 164-172.

Wahdani, A., K, Yaqin., N, Rukminasari., Suwarni., Nadiarti., D, F. Inaku., L, Fachruddin. 2020.

Konsentrasi mikroplastik pada Kerang Manila Venerupis philippinarum di Perairan Maccini Baji, Kecamatan Labakkang, Kabupaten Pangkajen Kepulauan, Sulawesi Selatan. Maspari Journal. 12(2): 1-13.

Widianarko, B., I, Hantoro. 2018. Mikroplastik dalam Seafood dari Pantai Utara Jawa. Semarang: Universitas Katolik Soegijapranata.

Woods, M. N., M, E. Stack., D, M. Fields., S, D. Shaw., P, A. Matrai. 2018. Microplastic Fiber Uptake, Ingestion, and Egestion Rates in the Blue 
Mussel (Mytilus edulis) Marine Pollution Bulletin. 137: 638-645.

Yamane, T. 1967. Statistics: an Introductory Analysis. New York: Harper and Row.

Zalmita, N., Y, Alvira., M, H. Furqan. 2020. Analisis Perubahan Penggunaan Lahan Menggunakan Sistem Informasi Geografis (Sig) di gampong Alue Naga Kecamatan Syiah Kuala Tahun 2004-2019. Jurnal Geografi. 9(1): 1-9. 